10

\title{
Оптическая эффективность люминесцентного солнечного концентратора на основе оксифторидного стекла с молекулярными кластерами серебра
}

\author{
() Д.С. Агафонова ${ }^{1}$, А.И. Сидоров ${ }^{1,2 \uparrow, ~ С . А . ~ Т а р а с о в ~}{ }^{1}$ \\ ${ }^{1}$ СПбГЭТу „лЭТи“, \\ 197376 Санкт-Петербург, Россия \\ ${ }^{2}$ Университет ИТМО, \\ 197101 Санкт-Петербург, Россия \\ e-mail: sidorov@oi.ifmo.ru
}

Поступила в редакцию 02.12.2019 г.

В окончательной редакции 01.04.2020 г.

Принята к публикации 03.06.2020 г.

\begin{abstract}
Показано, что оксифторидное стекло с люминесцентными молекулярными кластерами серебра перспективно в качестве люминесцентного солнечного концентратора (ЛСК) для преобразования УФ излучения Солнца в видимое излучение или в качестве первого каскада многослойного ЛСК. При численном моделировании использовались экспериментальные данные по поглощению и люминесценции указанного стекла. Спектральная оптическая эффективность ЛСК достигает 17.7\% для диапазона длин волн $310-475 \mathrm{~nm}$, интегральная эффективность - 12\%. Зеркальный отражатель на боковых гранях увеличивает эффективность ЛСК. Уменьшение толщины ЛСК и увеличение площади его поверхности увеличивает степень концентрации фотонов.
\end{abstract}

Ключевые слова: люминесценция, молекулярный кластер серебра, люминесцентный солнечный концентратор, спектральное преобразование, оптическая эффективность.

DOI: $10.21883 /$ OS.2020.10.50025.325-20

\section{Введение}

Использование солнечной энергии перспективно ввиду ее экологичности и доступности. Солнце создает в верхних слоях атмосферы Земли облученность в среднем $1361 \mathrm{~W} / \mathrm{m}^{2}$ [1], что может полностью покрыть потребности человечества в энергии. Однако экономические характеристики солнечных элементов, в том числе фотоэлектрических преобразователей (ФЭП), не позволяют внедрять их массово. Поэтому повышение эффективности и уменьшение стоимости солнечных элементов является актуальной задачей.

Эффективность преобразования излучения Солнца может быть увеличена, во-первых, при использовании спектрального преобразования коротковолнового излучения в длинноволновую область спектра, соответствующую спектральной чувствительности ФЭП (даунконверсия) [2]. Во вторых, эффективность преобразования может быть увеличена за счет концентрирования излучения на ФЭП небольшой площади. Концентраторы второго типа строятся на основе зеркальных и линзовых элементов. Они, как правило, имеют сложную конструкцию, требуют охлаждения и систем слежения за Солнцем, так как обладают низкой эффективностью при диффузном освещении [3]. Люминесцентные солнечные концентраторы (ЛСК) позволяют объединить оба подхода.
C точки зрения геометрии солнечные концентраторы могут быть прямоугольными, цилиндрическими, а также в виде оптических волокон [4-9]. В простейшем случае ЛСК является люминесцентной пластиной произвольной геометрии, к одному из торцов которой прикреплен ФЭП. Солнечное излучение возбуждает люминесценцию в пластине, которая является одновременно и оптическим волноводом. Излучение люминесценции при выполнении условия полного внутреннего отражения в виде волноводных мод направляется к торцам, где может быть преобразовано в электрический сигнал ФЭП. Механизм люминесценции обеспечивает спектральное преобразование, а геометрия ЛСК - концентрирование излучения на ФЭП меньшей площади. Чаще всего рассматриваются ЛСК прямоугольной формы с ФЭП, закрепленном на одном или нескольких торцах пластины $[7,8]$. Важной особенностью ЛСК является то, что угол падения излучения незначительно влияет на эффективность его преобразования, поэтому ЛСК работают как с прямым излучением Солнца, так и с косым, и с рассеянным. Для наибольшего охвата спектра Солнца ЛСК может состоять из нескольких каскадов, каждый из которых оптимизирован для определенного спектрального диапазона [10]. Для более эффективного сбора излучения люминесценции могут быть использованы отражатели на разных гранях ЛСК [11]. Дальнейшее увеличение эффективности может быть достигнуто в 
голографических ЛСК [12] и ЛСК с фильтрами, в том числе жидкокристаллическими [13].

Спектральные характеристики (поглощение, люминесценция, квантовый выход) материала ЛСК являются определяющими для возможности его эффективного использования. В условиях значительной облученности фотостабильность материала, особенно под действием УФ излучения, становится также важным параметром. В качестве люминофоров, как правило, используют органические красители, растворенные в полимере, ионы редкоземельных элементов и квантовые точки в органических и неорганических матрицах [13-20]. С точки зрения практического применения более перспективными для ЛСК являются люминесцентные неорганические стекла и стеклокерамики [20]. Они обладают высокой химической и термической стойкостью, а также устойчивостью к воздействию УФ излучения. Из люминесцентных стекол могут быть изготовлены как пластины, так и оптические волокна для ЛСК. Люминесцентными центрами в таких материалах могут быть полупроводниковые квантовые точки или молекулярные кластеры металлов [20-24].

Для субнаноразмерных нейтральных молекулярных кластеров (МК) металлов $\left(\mathrm{Ag}_{n}, \mathrm{Au}_{n}, \mathrm{Cu}_{n}, n=2-10\right)$ в стеклах характерна интенсивная люминесценция в видимой области спектра при возбуждении УФ излучением [22-24]. Размер кластера, его структура и состав окружающей матрицы определяют спектральные характеристики возбуждения и люминесценции МК. Молекулярные кластеры серебра могут быть сформированы в оптических стеклах в процессе их синтеза [22] или с помощью метода ионного обмена [25]. Люминесценция МК серебра может быть использована для спектрального преобразования излучения в белых светодиодах, солнечных элементах и при разработке различных устройств фотоники $[21,26,27]$.

Достоинством оксифторидных стекол является то, что в них может быть введено до $10 \%$ серебра и благодаря этому увеличена интенсивность люминесценции. Кроме того, они обладают высокой химической стойкостью. Однако до настоящего времени оксифторидные стекла с серебром не рассматривались в качестве кандидатов для люминесцентных концентраторов солнечного излучения.

Целью настоящей работы являлась оценка возможности использования оксифторидного стекла с МК серебра в качестве ЛСК для коротковолнового излучения Солнца. Для этого было синтезировано соответствующее стекло, измерены спектральные характеристики его поглощения, люминесценции и квантового выхода. С использованием измеренных спектральных характеристик был проведен расчет оптической эффективности ЛСК разных размеров, в том числе содержащих два ФЭП и зеркальные отражатели.

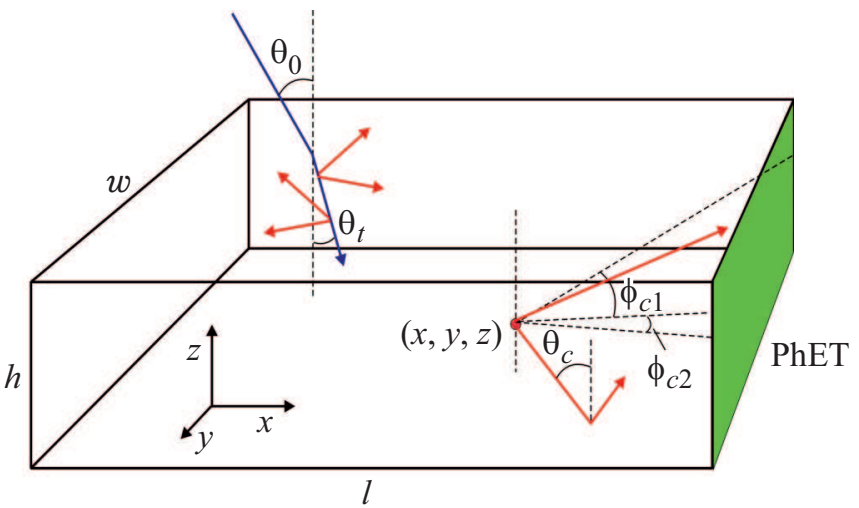

Рис. 1. Геометрия и траектории лучей в ЛСК с одним ФЭП (PhET). Пояснения в тексте.

\section{Методики экспериментов и расчетов}

\section{Синтез оксифторидных стекол с молекулярными кластерами серебра}

Оксифторидные стекла состава (50) $\mathrm{SiO}_{2}-(16) \mathrm{AlF}_{3}-$ (11) $\mathrm{PbF}_{2}-(20.5) \mathrm{CdF}_{2}-(2.5) \mathrm{ZnF}_{2}$ (в скобках указана концентрация в mol.\%) с добавкой $\mathrm{AgNO}_{3}(5 \mathrm{~mol} . \%)$ были изготовлены на кафедре технологии стекла СПбГТИ(ТУ). Синтез стекол проводился в течение $0.5-1 \mathrm{~h}$ в корундовых тиглях в атмосфере воздуха при температуре $950^{\circ} \mathrm{C}$. Фторидная матрица и ионы свинца создают для ионов серебра слабую восстановительную среду, что приводит к восстановлению ионов серебра до нейтральных атомов в процессе варки стекла и охлаждения расплава. При этом также образуются нейтральные МК серебра $\mathrm{Ag}_{n}(n=2-5)$, обладающие люминесценцией [23]. Образцы синтезированных стекол имели слабовыраженную желтую окраску.

\section{Методики измерений}

Спектр поглощения стекла был измерен с помощью спектрофотометра Lambda 650. Спектры люминесценции и квантовый выход люминесценции были измерены с помощью спектрометра C9920-02G (Hamamatsu) с интегрирующей сферой. Центральная длина волны в спектре возбуждающего излучения варьировалась в диапазоне $360-450 \mathrm{~nm}$ с шириной полосы на полувысоте $\sim 5 \mathrm{~nm}$.

\section{Методика расчетов}

Одной из основных характеристик ЛСК является оптическая эффективность (ОЭ) $O E$, показывающая долю падающего излучения, преобразованного в излучение с большей длиной волны и в виде волноводных мод дошедшего до ФЭП [17]. Спектральная ОЭ может быть определена как

$$
O E(\lambda)=P_{\text {ou }}(\lambda) / P_{\text {in }}(\lambda),
$$


где $P_{\text {in }}(\lambda)-$ спектральная характеристика мощности излучения на верней поверхности ЛСК, $P_{\text {out }}(\lambda)-$ спектральная характеристика мощности излучения на выходном торце ЛСК, сопряженном с ФЭП (рис. 1). При наличии нескольких ФЭП мощности на каждом торце складываются. Оптическая эффективность в спектральном диапазоне $\lambda_{\min } \ldots \lambda_{\max }$ равна

$$
O E=\frac{\int_{\min }^{\lambda_{\max }} P_{\text {out }}(\lambda) d \lambda}{\int_{\lambda_{\min }}^{\lambda_{\max }} P_{\text {in }}(\lambda) d \lambda} .
$$

С учетом различных механизмов потерь ОЭ может быть определена [5] как

$$
O E=(1-R) \eta_{a b s} \eta_{\mathrm{qy}} P_{\mathrm{tir}} \eta_{\mathrm{st}} \eta_{h} \eta_{\mathrm{tir}} \eta_{\mathrm{self}}
$$

где $R$ - коэффициент отражения падающего излучения от верней поверхности ЛСК; $\eta_{a b s}$ - доля поглощенного падающего излучения; $\eta_{\text {qу }}-$ квантовый выход люминесценции; $\eta_{\mathrm{st}}$ - коэффициент, учитывающий потери, обусловленные перекрытием спектров поглощения и люминесценции (стоксов сдвиг); $\eta_{\mathrm{tir}}-$ потери за счет неоднородностей на поверхности ЛСК; $\eta_{h}-$ эффективность передачи излучения люминесценции через стекло, окружающее люминофор; $\eta_{\text {self }}-$ коэффициент, учитывающий потери за счет поглощения излучения люминесценции другими люминофорами (при наличии композиции люминофоров в ЛСК); $P_{\text {tir }}$ - эффективность захвата излучения люминесценции. Множители в выражении (3) даны в порядке действия механизмов потерь в процессе захвата и преобразования солнечного излучения.

В данной работе мы рассматриваем потери излучения люминесценции внутри ЛСК совместно, в этом случае спектральная ОЭ равна

$$
O E(\lambda)=(1-R) \eta_{a b s}(\lambda) \eta_{\mathrm{qy}}(\lambda) P_{\mathrm{tir}} \eta_{\mathrm{loss}}(\lambda),
$$

где $\eta_{\text {loss }}$ - коэффициент, учитывающий потери излучения люминесценции за счет поглощения материалом ЛСК, включая люминесцентные центры и окружающую их среду. Границы ЛСК считаем идеальными $\left(\eta_{\text {tir }}=1\right)$. Интегральная ОЭ равна

$$
O E^{\mathrm{int}}=\frac{\int_{\min }^{\lambda_{\max }} O E(\lambda) d \lambda}{\lambda_{\max }-\lambda_{\min }} .
$$

Геометрия и траектории лучей в ЛСК показаны на рис. 1. Коэффициент отражения падающего излучения заданной поляризации определяется формулами Френеля. Доля поглощенного нормально падающего излучения $\eta_{a b s}$ равна

$$
\eta_{a b s}(\lambda, h)=1-\exp (-\alpha(\lambda) h),
$$

где $h$ - толщина пластины ЛСК, $\alpha(\lambda)$ - коэффициент поглощения пластины ЛСК. Для рассеянного (диффуз- ного) излучения

$$
\eta_{a b s}(\lambda, h)=\frac{1}{\pi} \int_{-\pi / 2}^{\pi / 2}\left\{1-\exp \left[\frac{\alpha(\lambda) h}{\cos \theta_{t}}\right]\right\} d \theta_{t},
$$

где $\theta_{t}-$ угол преломления на границе пластины ЛСК (рис. 1).

Ввиду простоты геометрии рассматриваемого ЛСК и его относительно больших габаритов анализ распространения излучения внутри ЛСК можно вести с точки зрения геометрической оптики. Введем коэффициент распространения $k_{\text {prop}}$, учитывающий захват излучения люминесценции за счет полного внутреннего отражения (ПВО) и потери излучения люминесценции внутри ЛСК за счет поглощения $\left(k_{\text {prop }}=P_{\text {tir }} \eta_{\text {loss }}\right)$ :

$$
k_{\text {prop }}(x, y)=\frac{2}{\pi} \int_{0}^{\pi / 2-\theta_{c}} \exp [-\alpha f(x, y, \theta)] d \theta,
$$

где $\theta_{c}=\arcsin (1 / n)-$ критический угол ПВО; $f(x, y, \theta)$ - геометрический путь луча от точки возбуждения люминесценции до ФЭП; $n-$ показатель преломления стекла. Если учесть, что луч может претерпеть ПВО на двух границах ЛСК (сбоку и сверху) и геометрическое место точки по оси у не влияет на долю дошедшего до ФЭП излучения, то

$$
k_{\text {prop }}=\frac{4}{\pi^{2}} \int_{0}^{\pi / 2-\theta_{c}} \int_{0}^{\pi / 2-\theta_{c}} \exp \frac{-\alpha x}{\cos (\theta) \cos (\phi)} d \theta d \phi,
$$

где $\theta$ и $\phi$ определяют возможные углы падения косого луча относительно двух границ ЛСК. В общем случае коэффициент $k_{\text {prop }}$ является спектрально зависимым ввиду зависимости $\alpha(\lambda)$.

Из геометрических соображений для точек возбуждения люминесценции, расположенных достаточно близко к ФЭП, так, что луч напрямую попадает на торец, минуя отражение от боковой границы ЛСК, существует определенная доля лучей с текущим углом, превышающим $\pi / 2-\theta_{c}$, которая попадает в ФЭП. В соответствии с рис. 1 введем две доли таких лучей по обе стороны от перпендикуляра, проведенного от точки с текущей координатой к ФЭП. В этом случае $k_{\text {prop }}^{i}$ равен:

$$
k_{\text {prop }}^{i}=\frac{1}{\pi^{2}} \int_{\pi / 2-\theta_{c}}^{\operatorname{arctg}\left(\frac{h-z}{x}\right)} \int_{0}^{\phi_{c i}} \exp \left(-\frac{\alpha x}{\cos \theta \cos \phi_{i}}\right) d \phi_{i} d \theta,
$$

где $i=1,2 ; \phi_{c 1}-\operatorname{arctg}[(w-y) / x], \phi_{c 2}=\operatorname{arctg}(y / x)-$ максимальные углы, при которых луч еще попадает на ФЭП (рис. 1).

В расчетах предполагается, что эти добавки $k_{\text {prop }}^{i} \neq 0$ только для точек, достаточно близких к ФЭП, когда 

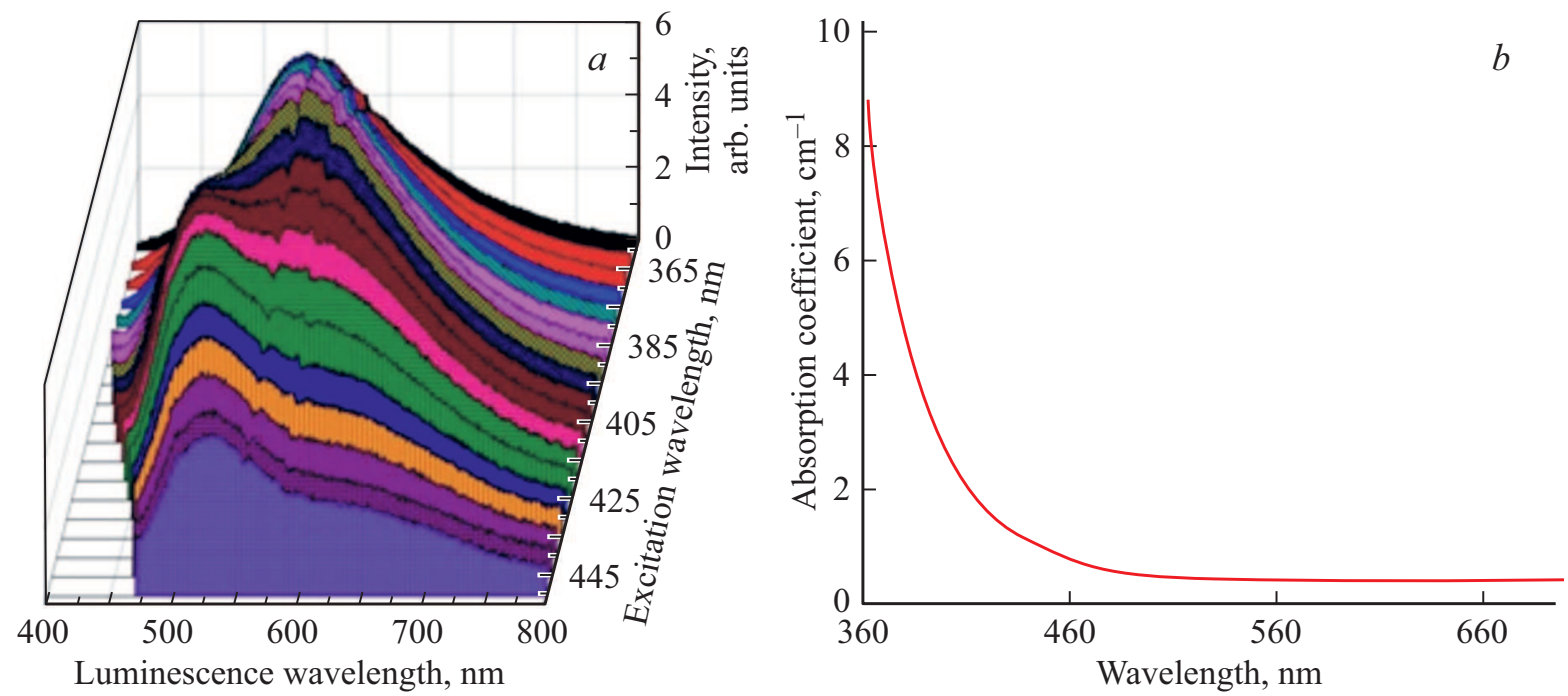

Рис. 2. Спектральные характеристики оксифторидного стекла с МК серебра. $a-$ спектры люминесценции для разных длин волн возбуждения, $b-$ спектр поглощения.

текущий угол $\theta$ превышает $\pi / 2-\theta_{c}$. Для этого должны выполняться следующие условия:

$$
\begin{cases}\frac{h-z}{x} \geqslant \operatorname{tg}\left(\frac{\pi}{2}-\theta_{c}\right) & \text { для } i=1, \\ \frac{z}{x} \geqslant \operatorname{tg}\left(\frac{\pi}{2}-\theta_{c}\right) & \text { для } i=2 .\end{cases}
$$

Полный коэффициент распространения равен

$$
K_{\text {prop }}(x, y, z, h, w)=k_{\text {prop }}+k_{\text {prop }}^{1}+k_{\text {prop }}^{2} .
$$

Интегральный коэффициент распространения равен

$$
k_{\text {prop }}^{\mathrm{int}}(h, l, w)=\iiint K_{\text {prop }}(x, y) d x d y d z,
$$

где $h, l$ и $w$ - толщина, длина и ширина ЛСК соответственно (рис. 1).

Спектральная ОЭ равна

$$
O E\left(\lambda, h, l, w=(1-R) \eta_{\mathrm{abs}}(h, \lambda) \eta_{\mathrm{qy}}(\lambda) k_{\mathrm{prop}}^{\mathrm{int}}(h, l, w),\right.
$$

где $\eta_{\text {qу }}-$ квантовый выход люминесценции. Интегральная ОЭ $\left(O E^{\text {int }}\right)$ определяется выражением (5).

В случае, если на боковых поверхностях ЛСК (грани $h, l$ на рис. 1) расположены зеркальные отражатели с коэффициентом отражения $R_{\mathrm{mir}}$, коэффициент распространения будет равен

$$
k_{\text {prop }}^{\text {mir }}=R_{\text {mir }} \frac{4}{\pi^{2}} \int_{0}^{\pi / 2-\theta_{c}} \int_{0}^{\pi / 2} \exp \frac{-\alpha x}{\cos \theta \cos \phi} d \theta d \phi .
$$

К важным параметрам ЛСК также относятся [4]:

- геометрический фактор усиления - отношение площади верхней поверхности ЛСК $S_{\text {apr }}$ к площади грани с ФЭП $S_{\text {edge }}: G_{g}=S_{\text {apr }} / S_{\text {edge; }}$;

- степень концентрирования фотонов: $C_{p}=G_{p} O E$.

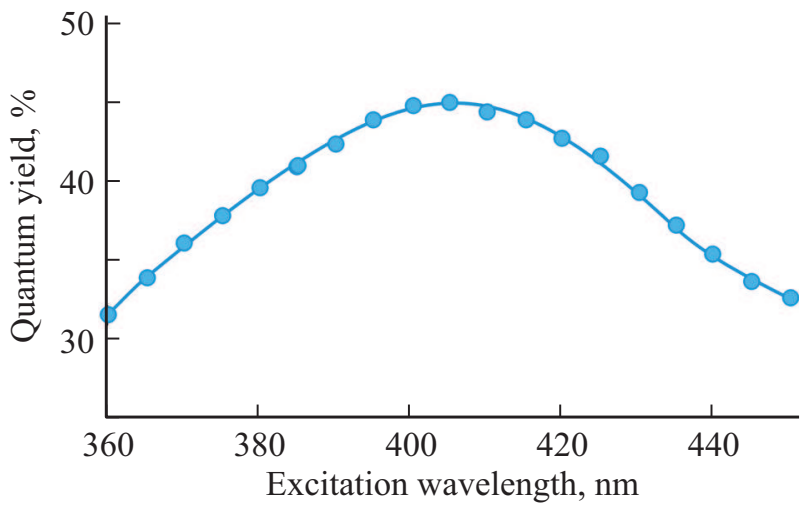

Рис. 3. Квантовый выход люминесценции оксифторидного стекла с МК серебра.

Для геометрии ЛСК, показанной на рис. 1, степень концентрирования фотонов равна

$$
C_{p}=\frac{l}{h} O E^{\mathrm{int}}
$$

\section{Экспериментальные результаты}

На рис. 2 представлены спектральные характеристики люминесценции и поглощения оксифторидного стекла, содержащего МК серебра. Из рисунка видно, что полоса люминесценции структурирована и занимает широкий спектральный диапазон $(\lambda=450-800 \mathrm{~nm})$. Согласно $[28,29]$, вклад в люминесценцию вносят атомы серебра и нейтральные МК серебра $\operatorname{Ag}_{n}(n=2-4)$. При увеличении длины волны возбуждения происходит смещение максимума спектра люминесценции в коротковолновую область. Край полосы поглощения приходится 
приблизительно на $420 \mathrm{~nm}$, что делает данный материал перспективным для даун-конвертеров коротковолнового излучения Солнца. Квантовый выход люминесценции для данного стекла варьирует в диапазоне 30-45\% в зависимости от длины волны возбуждения (рис. 3). Это является хорошим показателем для данного типа стекол. Максимум квантового выхода приходится на длину волны $405 \mathrm{~nm}$.

Полученные спектральные характеристики оксифторидного стекла с МК серебра позволяют методами численного моделирования оценить возможность использования данного материала в ЛСК.

\section{Результаты численного моделирования}

Основываясь на экспериментальных результатах, полученных для оксифторидного стекла с МК серебра, был произведен расчет однослойного ЛСК, содержащего
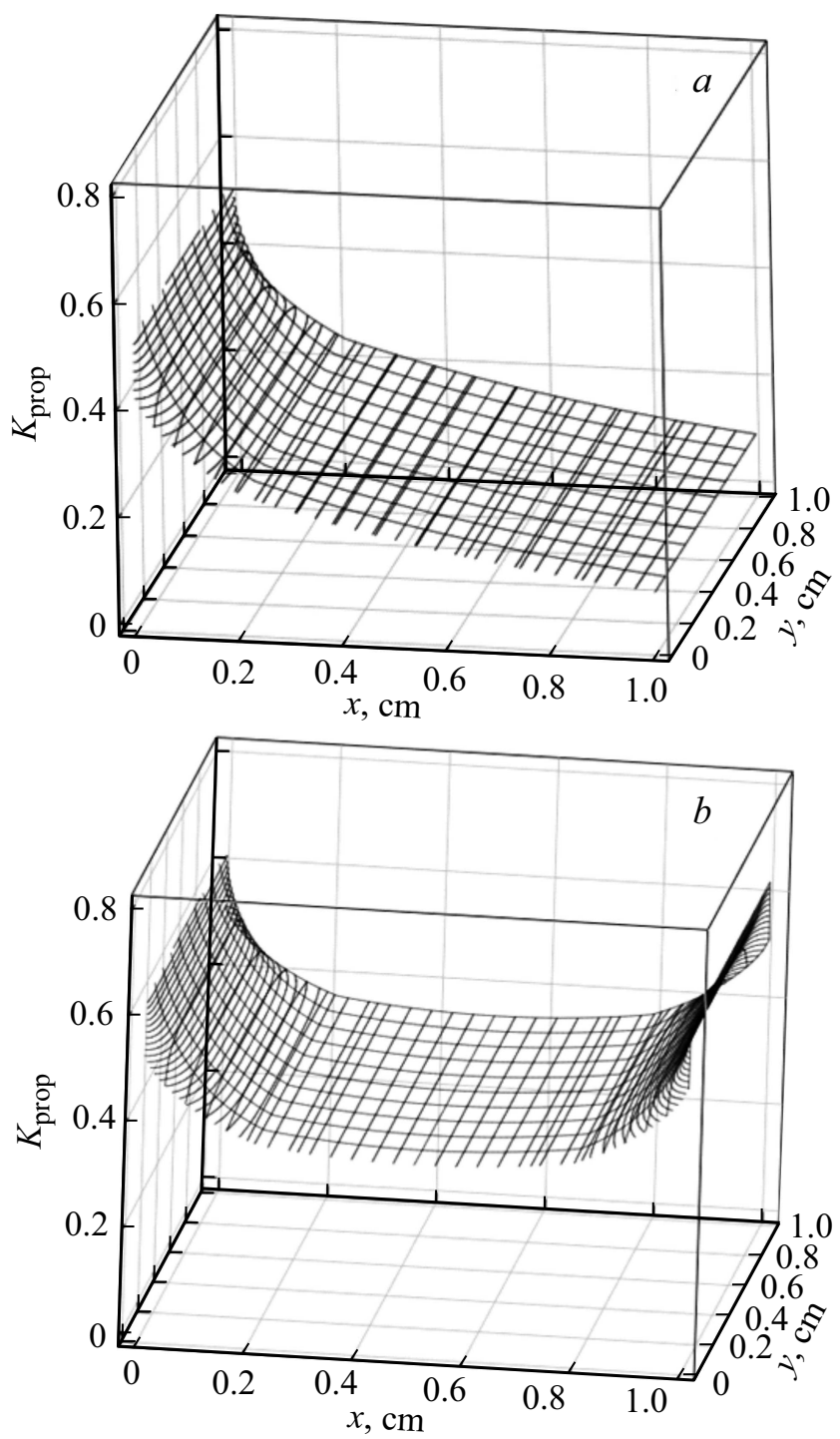

Рис. 4. Зависимость $K_{\text {prop }}(x, y)$ для ЛСК с одним $(a)$ и двумя $(b)$ ФЭП.

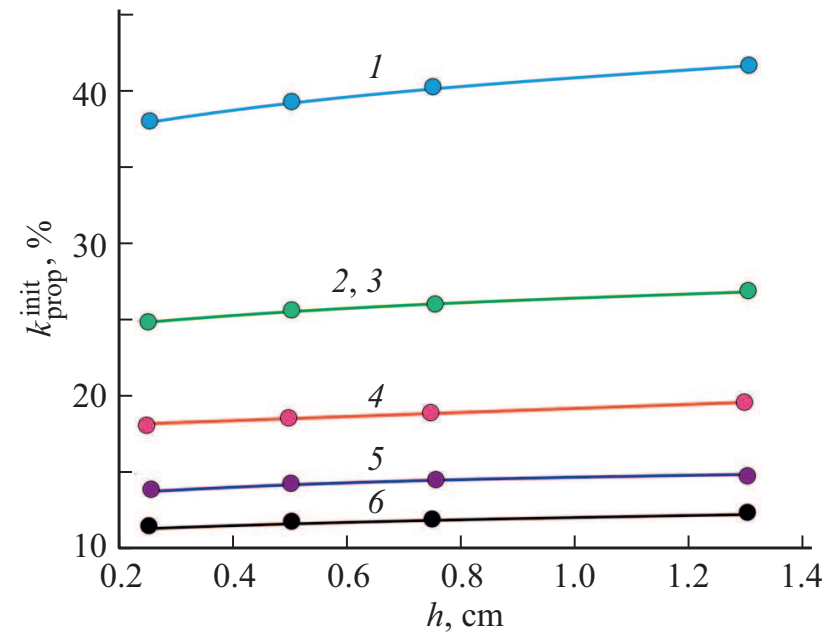

Рис. 5. Зависимость параметра $k_{\text {prop }}^{\text {int }}(w, l, h)$ от толщины $h$ для ЛСК с двумя ФЭП для различных размеров ЛСК $w \times l, \mathrm{~cm}$ : $1-1 \times 1,2-1 \times 2,3-2 \times 2,4-3 \times 3,5-4 \times 4,6-$ $5 \times 5$.

две панели ФЭП на противоположных торцах пластины. В данном рассмотрении также была учтена возможность использования зеркальных отражателей на боковых гранях. Ввиду слабой спектральной зависимости $\alpha(\lambda)$ в диапазоне люминесценции $(\lambda=450-800 \mathrm{~nm})$ (рис. 2) было принято допущение $\alpha(\lambda)=\alpha(570 \mathrm{~nm})$.

На рис. 4 представлены зависимости $K_{\text {prop }}(x, y)$ для ЛСК с параметрами $w=1 \mathrm{~cm}, l=1 \mathrm{~cm}, h=0.5 \mathrm{~cm} \mathrm{c}$ одним $(a)$ и двумя $(b)$ ФЭП без зеркальных отражателей. Чем дальше точка возбуждения люминесценции по оси $x$ от торца с ФЭП, тем меньшая ее доля доходит до ФЭП, причем уже для малых расстояний $(l=1 \mathrm{~cm})$ уменьшение этой доли излучения составляет около 2.8-3.0 раз для одного ФЭП. На рис. 5 представлена зависимость параметра $k_{\text {prop }}^{\text {int }}(w, l, h)$ при изменении толщины $h$ пластины от 0.25 до $1.3 \mathrm{~cm}$ для ЛСК с двумя ФЭП без зеркальных отражателей. Ввиду простоты конструкции ЛСК $k_{\text {prop }}^{\text {int }}$ для двух ФЭП равна $2 k_{\text {prop }}^{\text {int }}$ для одного ФЭП. При увеличении площади ЛСК зависимости $K_{\text {prop }}(x, y)$ приобретают больший наклон, таким образом интегральное значение $k_{\text {prop }}^{\text {int }}$ уменьшается. При этом все меньшая доля от суммарного потока излучения люминесценции доходит до ФЭП. Изменение толщины пластины ЛСК в меньшей степени влияет на данный параметр. Рост $k_{\text {prop }}^{\text {int }}$ при увеличении толщины обусловлен увеличением вклада добавочных коэффициентов $k_{\text {prop }}^{1}$ и $k_{\text {prop }}^{2}$ (выражения (10) и (11)). При увеличении площади верхней грани ЛСК в 25 раз интегральный коэффициент распространения уменьшается приблизительно в 3.3 раза.

Основываясь на выражениях (4) и (5), были определены спектральная и интегральная ОЭ ЛСК разной геометрии без зеркальных отражателей для диапазона длин волн возбуждения люминесценции $300-475 \mathrm{~nm}$. 

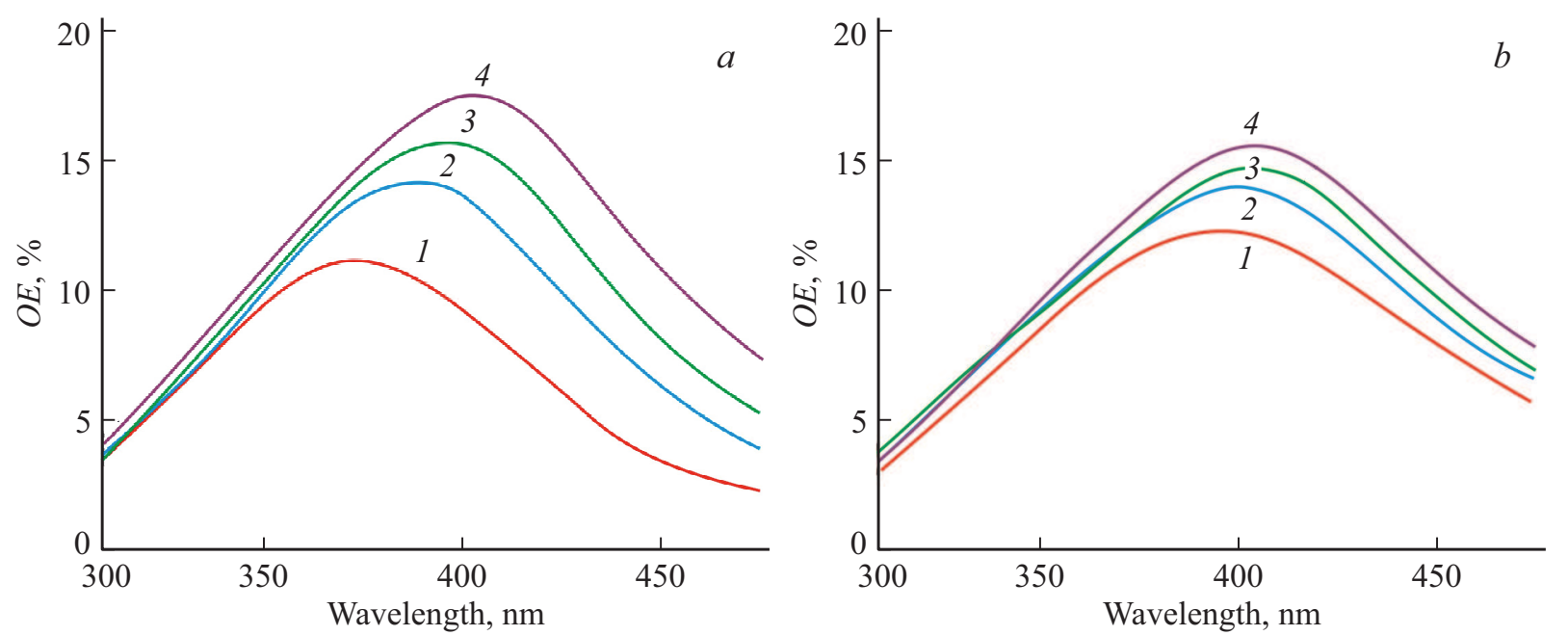

Рис. 6. Спектральная оптическая эффективность $O E(\lambda, h, w, l)$ ЛСК без зеркальных отражателей размером $1 \times 1 \mathrm{~cm}$ для разной толщины $h$ пластины: $h=0.25(1), 0.5(2), 0.75(3), 1.3 \mathrm{~cm}(4) . a-$ нормальное падение излучения Солнца, $b-$ диффузное излучение.

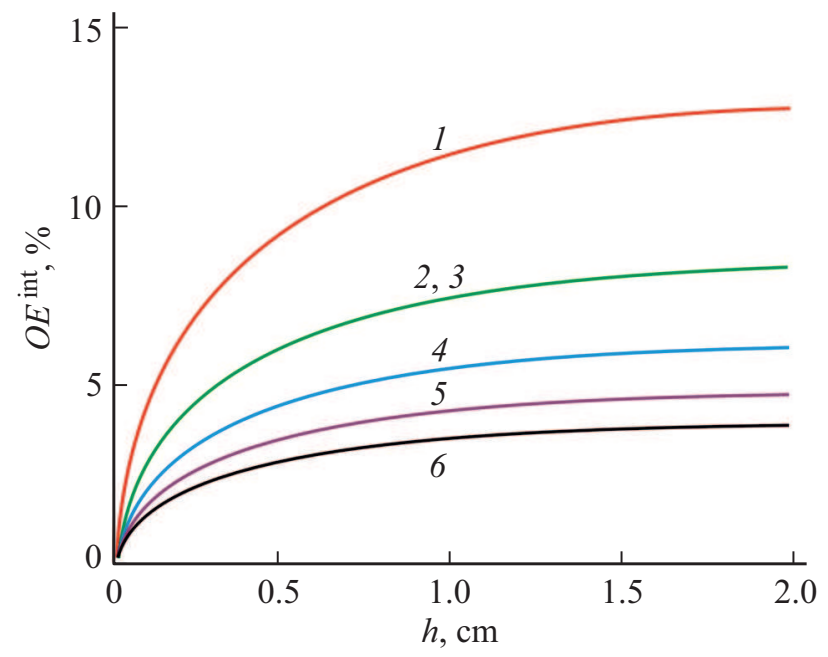

Рис. 7. Интегральная оптическая эффективность в зависимости от толщины $O E^{\text {int }}(h, w, l)$ для ЛСК разных размеров $w \times l, \mathrm{~cm}: 1-1 \times 1,2-1 \times 2,3-2 \times 2,4-3 \times 3,5-$ $4 \times 4,6-5 \times 5$.

Результаты моделирования показаны на рис. 6 и 7. Расчеты проведены как для нормального падения солнечного излучения, так и для диффузного. Диффузное излучение моделировалось при учете угловой характеристики отражения (пропускания) при прохождении излучения через пластину стекла с использованием формул Френеля. Из рисунков видно, что угловое распределение падающего излучения оказывает значительно меньшее влияние на ОЭ, чем геометрия ЛСК. При этом увеличение толщины повышает спектральную и интегральную ОЭ за счет большей доли поглощенного излучения. В то же время расчеты показывают, что увеличение диагонали ЛСК (длины и ширины) приводит к уменьшению ОЭ ввиду сильного влияния потерь излучения внутри пластины. Для меньших толщин ЛСК диффузное излучения Солнца дает более эффективное возбуждение излучения, чем прямое (максимум спектральной ОЭ смещается в длинноволновую область). Это обусловлено увеличением пути косых лучей через ЛСК, а значит, и увеличением доли поглощенного излучения. Благодаря этому появляется добавка в длинноволновой области, где, вообще говоря, коэффициент поглощения ниже. Однако спектральный сдвиг максимума ОЭ незначителен, поскольку квантовый выход люминесценции также уменьшается в длинноволновой части спектра (рис. 3). Спектральная и интегральная ОЭ для ЛСК размерами $1 \times 2$ и $2 \times 2 \mathrm{~cm}$ совпадают, поскольку увеличение только ширины ЛСК не дает выигрыша в доле собранного излучения. Это связано с тем, что площадь приемного торца с ФЭП также увеличивается. Таким образом, спектральная ОЭ ЛСК на основе оксифторидного стекла с МК серебра варьирует в пределах $1.1-17.7 \%$ для диапазона длин волн 310-475 nm, интегральная - достигает значения $\sim 12 \%$. Для сравнения ЛСК на основе полимера с добавкой люминесцентного красителя имеет ОЭ примерно $12 \%[12]$.

На рис. 8 показаны зависимости степени концентрирования фотонов $C_{p}$ для ЛСК разной площади в зависимости от толщины. Из рисунка видно, что для одного размера $w \times l$ увеличение толщины приводит к уменьшению параметра $C_{p}$, поскольку геометрический фактор усиления $G_{g}$ оказывает больший вклад, чем уменьшение интегральной ОЭ. Это также обусловливает то, что при фиксированной толщине $h$ наиболее эффективен ЛСК с большей площадью верхней грани, несмотря на то, что OEint при этом уменьшается.

В расчетных результатах, представленных выше, не проводилась коррекция на спектр излучения Солнца. В то же время моделирование показало, что введение 


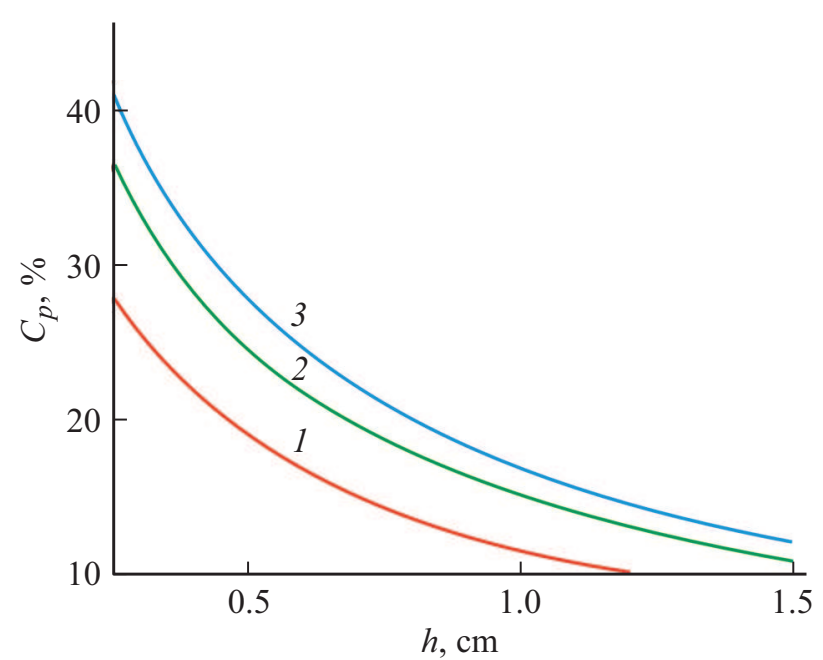

Рис. 8. Степень концентрирования фотонов $C_{p}(h, w, l)$ в зависимости от толщины для ЛСК разных размеров $w \times l, \mathrm{~cm}$ : $1-1 \times 1,2-2 \times 2,3-4 \times 4$.

Интегральная ОЭ и степень концентрирования фотонов ЛСК для $h=0.75 \mathrm{~cm}$ и диапазона $310-475 \mathrm{~nm}$. Коэффициент отражения зеркала $R_{\mathrm{mir}}=0.9$

\begin{tabular}{c|c|c|c|c}
\hline $\begin{array}{c}w \times l, \\
\mathrm{~cm}\end{array}$ & \multicolumn{2}{|c|}{$\begin{array}{c}\text { Интегральная ОЭ } \\
O E^{\text {int }}, \%\end{array}$} & \multicolumn{2}{c}{$\begin{array}{c}\text { Степень концентри- } \\
\text { рования фотонов } C_{p}\end{array}$} \\
\hline & Без зеркала & С зеркалом & Без зеркала & С зеркалом \\
\hline $1 \times 1$ & 10.69 & 12.46 & 14.25 & 16.62 \\
$1 \times 2$ & 6.93 & 7.87 & 18.48 & 20.99 \\
$2 \times 2$ & 6.96 & 7.87 & 18.55 & 20.99 \\
$3 \times 3$ & 5.03 & 5.62 & 20.11 & 22.47 \\
$4 \times 4$ & 3.90 & 4.33 & 20.78 & 23.08 \\
$5 \times 5$ & 3.17 & 3.51 & 21.13 & 23.41
\end{tabular}

коррекции на солнечный спектр АМ 1.5 в незначительной степени влияет на ход зависимостей $O E^{\text {int }}$. При этом наблюдается небольшой сдвиг характеристик в область больших толщин, а величина $O E^{\text {int }}$ изменяется на $1-2 \%$. Это обусловлено обеднением коротковолновой части в спектре АМ 1.5 по сравнению с неселективным источником, который изначально использовался в расчетной модели.

В таблице приведено сравнение параметров $O E^{\text {int }}$ и $C_{p}$ для ЛСК, содержащих и не содержащих зеркальные отражатели на боковых гранях. Из таблицы видно, что зеркальный отражатель увеличивает $O E^{\text {int }}$ на $0.34-1.77 \%$ и $C_{p}$ на $2.28-2.37 \%$. Причем для больших размеров ЛСК зеркальный отражатель мало влияет на $O E^{\text {int. }}$ В то же время для увеличения Сp зеркальный отражатель эффективен при любом размере ЛСК.

В качестве ФЭП для ЛСК может быть выбран элемент на основе монокристаллического кремния, для которого коэффициент согласования спектров люминесценции оксифторидного стекла с МК серебра и спектральной чувствительности может достигать 0.96 .

\section{Заключение}

Таким образом, спектральная ОЭ ЛСК на основе оксифторидного стекла с МК серебра варьирует в пределах $1.1-17.7 \%$ для диапазона длин волн $310-475 \mathrm{~nm}$, интегральная - достигает значения $\sim 12 \%$ (в зависимости от толщины пластины). Наличие зеркального отражателя приводит к росту ОЭ. Результаты показывают, что данный тип стекла перспективен в качестве ЛСК для коротковолнового излучения солнца или в качестве первого каскада многослойного ЛСК. Большей степенью концентрирования фотонов обладает ЛСК малой толщины и большой площадью верхней грани. Спектральное преобразование увеличивает чувствительность ФЭП к коротковолновому излучению. Преимуществом оксифторидного стекла является значительно бо́льшая устойчивость к воздействию УФ излучения и температуры по сравнению с органическими красителями.

\section{Финансирование работы}

Работа выполнена при финансовой поддержке Министерства образования и науки РФ в рамках НИР проектной части ГЗ, проект № 16.1750.2017/4.6.

\section{Благодарности}

Авторы выражают благодарность Е.В. Колобковой за синтез оксифторидных стекол.

\section{Конфликт интересов}

Авторы заявляют, что у них нет конфликта интересов.

\section{Список литературы}

[1] Coddington O., Lean J.L., Pilewskie P., Snow M., Lindho D. // BAMS. 2016. V. 97. P. 1265.

[2] Gallagher S.J., Rowan B.C., Doran J., Norton B. // Solar Energy. 2007. V. 81. P. 540.

[3] Sychugov I. // Optica. 2019. V. 6. P. 1046.

[4] Van Sark W.G.J.H.M., Barnham K.W.J., Slooff L.H., Chatten A.J., Büchtemann A., Meyer A., McCormack S.J., Koole R., Farrell D.J., Bose R., Bende E.E., Burgers A.R., Budel T., Quilitz J., Kennedy M., Meyer T., Doneg C.M., Meijerink A., Vanmaekelbergh D. // Opt. Express. 2008. V. 16. P. 21773.

[5] Rowan B.C., Wilson L.R., Richards B.S. // IEEE J. Sel. Top. Quant. Electron. 2008. V. 14. P. 1312.

[6] McIntosh K., Yamada N., Richards B.S. // Appl. Phys. B. 2007. V. 88. P. 285.

[7] Colantuono G., Buckley A., Erdélyi R. // J. Lightwave Technol. 2013. V. 31. P. 1033. 
[8] Inman R.H., Shcherbatyuk G.V., Medvedko D., Gopinathan A., Ghosh S. // Opt. Express. 2011. V. 19. P. 24308.

[9] Агафонова Д.С., Колобкова Е.В., Никоноров Н.В., Сидоров А.И. // Патент РФ № 2548576 от 23.03.2015.

[10] Barnham K., Marques J.L., Hassard J., O'Brien P. // Appl. Phys. Lett. 2000. V. 76. P. 1197.

[11] Rafiee M., Chandra S., Ahmed H., Mc Cormack S.J. // Opt. Mater. 2019. V. 91. P. 212.

[12] Castro J.M., Zhang D., Myer B., Kostuk R.K. // Appl. Opt. 2010. V. 49. P. 858

[13] De Boer D.K.G., Broer D.J., Debije M.G., Keur W., Meijerink A., Ronda C.R., Verbunt P.P.C. // Opt. Express. 2012. V. 20. P. A395.

[14] Edelenbosch O.Y., Fisher M., Patrignani L., van Sark W.G.J.H.M., Chatten A.J. // Opt. Express. 2013. V. 21. P. A503.

[15] Chatten A.J., Barnham K.W.J., Buxton B.F., EkinsDaukes N.J., Malik M.A. // Semiconductors. 2004. V. 38. P. 909.

[16] Sholin V., Olson J.D., Carter S.A. // J. Appl. Phys. 2007. V. 101. P. 123114.

[17] Krumer Z., Pera S.J., van Dijk-Moes R.J.A., Zhao Y., de Brouwer A.F.P., Groeneveld E., van Sark W.G.J., Schropp R.E.I., Donega C.M. // Opt. Nanostr. and Adv. Mater. 2012. P. PW2B. doi 10.1364/PV.2012.PW2B.3

[18] Sark W.G.J.H.M., Schropp R.E.I., de Mello-Donegá C. // Sol. Energy Mater. Sol. Cells. 2013. V. 111. P. 57.

[19] Debije M.G., Verbunt P.P.C. // Adv. Energy Mater. 2012. V. 2. N 1. P. 12.

[20] Афанасьев В.П., Васильев В.Н., Игнатьев А.И., Колобкова Е.В., Никоноров Н.В., Сидоров А.И., Цехомский В.А. // Оптический журнал. 2013. Т. 80. № 10. С. 69.

[21] Agafonova D.S., Sidorov A.I., Kolobkova E.V., Ignatiev A.I., Nikonorov N.V. // Proc. SPIE. 2014. V. 9141. P. 91411T.

[22] Dubrovin V. D., Ignatiev A. I., Nikonorov N. V., Sidorov A.I., Shakhverdov T.A., Agafonova D.S. // Opt. Mater. 2014. V. 36. P. 753.

[23] Колобкова Е.В., Никоноров Н.В., Сидоров А.И., Шахвердов T.A. // Опт. и спектр. 2013. Т. 114. С. 260.

[24] Nikonorov N., Sidorov A. In „Metal Nanoparticles: Properties, Synthesis and Applications", (Series: Nanotechnology Science and Technology) / Ed by. Y. Saylor, V. Irby. NY.: Nova Science Publishers, 2018. P. 61.

[25] Демичев И.А., Игнатьев А.И., Сгибнев Е.М., Демичев И.А., Никоноров Н.В., Сидоров А.И., Хрущева Т.А., Шахвердов T.A. // Опт. и спектр. 2014. Т. 116. № 4. C. $631-637$.

[26] Kuznetsov A.S., Tikhomirov V.K., Moshchalkov V.V. // Opt. Express. 2012. V. 20. P. 21576.

[27] Kuznetsov A.S., Tikhomirov V.K., Shestakov M.V., Moshchalkov V.V. // Nanoscale. 2013. V. 5. P. 10065.

[28] Fedrigo S., Harbich W., Buttet J. // J. Chem. Phys. 1993. V. 99. P. 5712.

[29] Felix C., Sieber C., Harbich W., Buttet J., Rabin I., Schulze W., Ertl G. // Chem. Phys. Lett. 1999. V. 313. P. 105. 